\title{
The epistemic significance of political disagreement
}

\author{
Hallsson, Bjørn Gunnar
}

Published in:

Philosophical Studies

DOI:

10.1007/s11098-018-1121-8

Publication date:

2019

Document version

Publisher's PDF, also known as Version of record

Citation for published version (APA):

Hallsson, B. G. (2019). The epistemic significance of political disagreement. Philosophical Studies, 176, 2187-2202. https://doi.org/10.1007/s11098-018-1121-8 


\title{
The epistemic significance of political disagreement
}

\author{
Bjørn G. Hallsson ${ }^{1}$ (1)
}

(C) Springer Science+Business Media B.V., part of Springer Nature 2018

\begin{abstract}
The degree of doxastic revision required in response to evidence of disagreement is typically thought to be a function of our beliefs about (1) our interlocutor's familiarity with the relevant evidence and arguments, and their intellectual capacities and virtues, relative to our own, or (2) the expected probability of our interlocutor being correct, conditional on our disagreeing. While these two factors are typically used interchangeably, I show that they have an inverse correlation in cases of disagreement about politically divisive propositions. This presents us with a puzzle about the epistemic impact of disagreement in these cases. The most significant disagreements on (1) are the least significant disagreements on (2), and vice versa. I show that assessing the epistemic status of an interlocutor by reference to either (1) or (2) has uncomfortable consequences in these cases. I then argue that this puzzle cannot be escaped by claiming that we usually have disputeindependent reason to reject the significance of politically charged disagreement altogether.
\end{abstract}

Keywords Epistemology of disagreement · Political disagreement · Motivated reasoning $\cdot$ Belief polarization

\section{Introduction}

Political life is rife with disagreement. We disagree with one another not only about questions of value, but also about policy-relevant matters of fact, such as whether anthropogenic global warming is occurring, whether gun control legislation reduces

Bjørn G. Hallsson

hallsson@hum.ku.dk

1 Section of Philosophy, Department of Media, Cognition, and Communication, University of Copenhagen, Karen Blixens Plads 8, 2300 Copenhagen, Denmark 
deaths from gun violence, or whether nuclear energy is safe. How should we rationally respond to such disagreements? Are we rationally required to become less confident in our contested political beliefs, including our politically charged factual beliefs, or can we permissibly remain confident in the face of controversy? While such political disagreement is rarely the primary focus, the epistemic significance of disagreement in general has become a widely debated issue in epistemology. While some have argued that the kinds of disagreements we encounter in the political domain are of epistemic significance, ${ }^{1}$ most of the debate in epistemology has focused on idealized cases of peer disagreement. That is, it has focused on the question of what the rational response is to the discovery of disagreement with someone whom you roughly consider your epistemic equal. ${ }^{2}$

There are two widely employed notions of epistemic peerhood in the literature. The first focuses on the disagreeing parties' familiarity with the relevant evidence in combination with relatively broad, stable character traits or epistemic virtues. For instance, Kelly (2005, p. 174) states that two individuals are epistemic peers with respect to a question if and only if they satisfy the following two conditions:

1. They are equals with respect to their familiarity with the evidence and arguments which bear on that question, and

2. They are equals with respect to general epistemic virtues such as intelligence, thoughtfulness, and freedom from bias.

There is a question here of what precisely equality is taken to mean. With respect to evidence, some philosophers suggest that to be equals is to have identical evidence (King 2012). However, there is good reason to think that what is epistemically significant, in the sense of determining the amount of doxastic change required upon the discovery of disagreement, is not equality in the sense of identity, but equality in the sense of parity. Suppose that you and I discover that we disagree about $p$, and that I have good reason to think that while your evidence about $\mathrm{p}$ differs from mine, it is just as good. This seems to provide me with as much reason to doubt the truth of my belief as your disagreeing on the basis of identical evidence does (Christensen 2007). ${ }^{3}$ Similar considerations apply to ability. What I will take to be epistemically significant is that the two parties to a disagreement are equally able, in the sense that they are generally equally good at responding to the evidence-not that they

\footnotetext{
${ }^{1}$ See e.g. Matheson (2015), Christensen (2014), Lackey (2008) and King (2012).

${ }^{2}$ In this article, my focus is on question of the epistemic significance of political disagreement. This is distinct from the political significance of persistent disagreement in the political domain as it is typically discussed in political philosophy in the Rawlsian tradition. For a recent discussion of how the epistemic question bears on the political, see Enoch (2017).

${ }^{3}$ One oft-cited reason why peer disagreements are epistemically significant is that they raise the possibility that one of the peers has made some mistake in their evaluation of the evidence. This possibility is certainly more salient in cases of identical evidence. But Christensen's case shows that it would be mistaken to think that this is the only kind of worry that peer disagreements can raise. To the extent that one's interest is investigating the epistemic significance of the kind of higher-order evidence of a cognitive malfunction that arises to a greater extent when there is evidential identity, one can add to epistemic peerhood a stipulation that there has been full disclosure of the evidence (Christensen 2010; Feldman 2006; Lackey 2008).
} 
respond to evidence in identical ways (Matheson 2015). So, roughly, two people are epistemic peers in the first sense if there is evidential and cognitive parity between them.

The second widely used notion of peerhood is from Elga (2007). On Elga's view, you count someone as your epistemic peer “....with respect to an about-to-be-judged claim if and only if you think that, conditional the two of you disagreeing about the claim, the two of you are equally likely to be mistaken" (2007, p. 499). In other words, I consider you to be my epistemic peer with respect to $\mathrm{p}$ if I think that, should it turn out that we disagree about $\mathrm{p}$, it is as likely that your belief is correct as it is that mine is. My assessment of how likely it is that each of our beliefs is correct will typically depend on what I believe about what evidence each of us have available and our ability to judge what that evidence supports.

The two notions of epistemic peerhood are, clearly, closely related. When I think that there is evidential parity between us, and that you are generally my equal with respect to intellectual virtues, then I am very likely to also think that we are equally likely to be right about $\mathrm{p}$, if it should it turn out that we disagree.

There is, appropriately enough for the topic, much disagreement among philosophers about what the best notion of epistemic peerhood is (Christensen 2016; Gelfert 2011), and about what doxastic revision, if any, is required when an individual discovers that they are party to a peer disagreement (Christensen and Lackey 2013; Feldman and Warfield 2010). What there does not seem to be any major disagreement about is that the factors captured in the two notions of peerhood are important determinants of how much doxastic revision is required in any given case of disagreement. When I find myself in a disagreement with someone whom I think is clearly my cognitive and evidential superior, there is widespread consensus that I should defer to his or her judgment. I should do the same if I find myself in a disagreement with someone whom I, antecedently to discovering the disagreement, thought much more likely to be correct about the matter than myself. At the other end of the spectrum, it is not very controversial that I should not be moved when I disagree with someone who has absolutely no evidence about the disputed matter, but I have great familiarity with much high-quality evidence. Neither should I be moved when I disagree with someone who is much, much worse than me at evaluating any evidence he or she might possess. Likewise, if I think that the probability that you are right conditional on our disagreeing is 0 , I should not be moved by the discovery that we disagree.

What this shows is that the extent of doxastic revision one's evidence requires in a case of disagreement is, at least in part, ${ }^{4}$ a function of one's interlocutor's familiarity with relevant evidence and their general intellectual virtues or cognitive ability, or of their probability of being correct. The intuition that someone's probability of being correct is coextensive with, or at least strongly correlates with, the combination of evidential quality and cognitive ability is, I think, the reason why most discussions in the epistemology of disagreement focus only on one of the two

\footnotetext{
${ }^{4}$ I do not wish to exclude the possibility that factors such as who actually got things right, or whether a belief is actually justified or not can also make a difference (Kelly 2010, 2013; Lackey 2008).
} 
notions of peerhood. However, it will be necessary to keep track of both notions for the remainder of this paper. For ease of reference, we can name them as follows:

ABILITY: An individual's familiarity with the relevant evidence and arguments, and their epistemic virtues such as intelligence, thoughtfulness, and freedom from bias.

ACCURACY: The probability of an individual's belief about $\mathrm{p}$ being correct, conditional on their disagreement with another individual.

Generally in cases of disagreement, holding any facts about myself constant, the higher I rate my interlocutor's ABILITY or ACCURACY, the more doxastic revision is required on my part.

In what follows, I argue that one's beliefs about an interlocutor's ABILITY and beliefs about their ACCURACY should be inversely correlated in cases of disagreement about politically charged facts. In such disagreements, the more familiar I believe you are with the relevant evidence, and the more reflective, intelligent, numerate, open-minded, scientifically literate, and well-educated I think you are, the more likely I should think it is that your are mistaken. This presents us with a puzzle about how we should determine the epistemic significance of our disagreement.

\section{Motivated cognition and political polarization of factual beliefs}

Our doxastic attitudes toward politically charged factual propositions, such as humans are causing global warming, or the death penalty is a deterrent to murder are likely to be influenced by motivated cognition (Corner et al. 2012; Kahan et al. 2012; Lord et al. 1979). By motivated cognition I mean cognition that aims at arriving at an interpretation of evidence that yields a desired conclusion-in this case, the conclusion that vindicates one's political views - rather than cognition that aims only at arriving at accurate beliefs (Kahan 2016; Kunda 1990; Van Bavel and Pereira 2018). For example, our motivations affect how we perceive ambiguous visual stimuli (Balcetis and Dunning 2006), or how we seek out and attend to information (Hart et al. 2009) in ways that favor politically desired conclusions. We are likely to selectively remember information that supports a desired conclusion, or to misremember information as more congenial to our desired conclusion than it in fact was (Hennes et al. 2016). We tend to selectively scrutinize evidence that counts against a desired conclusion, and to evaluate arguments in favor of our desired conclusions as much stronger than arguments against them (Taber and Lodge 2006; Van Bavel and Pereira 2018).

When under the influence of motivated reasoning, we (unbeknownst to ourselves) utilize our cognitive abilities to generate reasons in favor of a desired conclusion, and to fend off reasons against it. When faced with evidence against a desired conclusion, for example, we might employ our critical reasoning to finding justifications for disregarding the evidence. Those who are better at critical reasoning will be better at finding such reasons. When one's cognition is motivated 
at arriving at a particular conclusion, then the greater one's ABILITY, the better one is at making one's construal of the evidence yield the desired conclusion (Kahan 2013; Kahan et al. 2017; Kraft Lodge and Taber 2015).

This explains an otherwise strange fact about the distribution of doxastic attitudes about politically disputed propositions in the general population: Not only are beliefs polarized along political fault lines, such that political ideology is highly predictive of one's belief about these propositions, but the degree of polarization correlates positively with familiarity with relevant evidence, and with measures of cognitive ability, numerical reasoning skills, education, scientific literacy, and even with intellectual virtues such as open-mindedness and reflectiveness (Hamilton 2011; Kahan et al. 2012; Kahan and Corbin 2016; Kahan and Stanovich 2016; Taber and Lodge 2006). In other words, the greater a person's ABILITY, the more predictive that person's political ideology is of their beliefs about politically charged propositions, and the more likely they are to adopt extreme doxastic attitudes. To give an example, liberal democrats are likely to believe that humans are causing global warming, and their likelihood of believing this, and the certainty with which they hold the belief, increases with their familiarity with relevant evidence, education level, ability to inhibit intuitions and reflect on complex problems, their open-mindedness, scientific literacy, etc. In contrast, conservative republicans are likely to disbelieve that humans are causing global warming, and their likelihood of disbelieving it, and their certainty in their disbelief, increases with familiarity with relevant evidence, education level, ability to reflect, openmindedness, scientific literacy, etc. (Hamilton 2011; Kahan et al. 2012; Kahan and Corbin 2016). ${ }^{5}$

\section{The conflict between ABILITY and ACCURACY}

The above findings suggest that there is a conflict between ABILITY and ACCURACY in determining the epistemic significance of disagreements about politically divisive propositions. To see this, consider the following case:

BRILLIANT PARTISAN: I belong firmly on one side of the political aisle. I have a doxastic attitude toward a politically disputed proposition $\mathrm{p}$ that is typical for those on my side of the aisle. I learn that BP is an extremely intelligent, highly educated and scientifically literate, open-minded, and reflective person on the other side of the political aisle, who is intimately familiar with the relevant evidence about $\mathrm{p}$.

How epistemically significant should I consider any subsequent evidence that BP disagrees with me about $\mathrm{p}$ ? If I assess the epistemic significance of our disagreement

\footnotetext{
5 This pattern is even stronger when, rather than looking at political partisanship or ideology, one looks at individuals' cultural commitments- the degree to which they prefer market-driven, bottom up solutions to social problems over collective and top-down ones, and the degree to which they prefer relatively stratified social organizations with clear power- and status differentials over more egalitarian ones (Kahan 2012).
} 
by reference to BP's ABILITY, then it would seem that I should find it quite significant. After all, BP scores highly on virtually all the defining qualities of ABILITY. But if I assess the epistemic significance of our disagreement with respect to ACCURACY, then it seems that I should find BP's disagreement relatively less significant. Given what I know about BP, I think it highly likely that he or she has adopted an extreme doxastic attitude toward $\mathrm{p}$ in the opposite direction of my own. I think that it is very unlikely that BP's belief would be correct if this were the case-I just couldn't fathom how the publically available evidence about $p$ could strongly support the falsity of my own belief. Conditional on our disagreeing about $\mathrm{p}, \mathrm{I}$ think it is very unlikely that BP is correct.

So, ABILITY and ACCURACY yield different verdicts about the epistemic significance of this case. But the discrepancy does not end here. Consider the following variation on the case:

MEDIOCRE PARTISAN: I belong firmly on one side of the political aisle. I have a doxastic attitude about a politically disputed proposition $\mathrm{p}$ that is typical for those on my side of the aisle. I learn that MP is a moderately intelligent, decently educated and scientifically literate, somewhat openminded, and reasonably reflective person from the other side of the political aisle, who has some familiarity with the relevant evidence.

With respect to ABILITY, I should give less weight to the disagreement of MP than I did to the disagreement of BP. This seems quite clear: There is no intellectual virtue that MP has to a greater extent than $\mathrm{BP}$, and there are several that MP has to a lesser extent, including lesser familiarity with the relevant evidence. But on ACCURACY, it can be argued that I should give more weight to the disagreement of MP than I gave to the disagreement of BP. In light of MP's lesser virtuousness, he or she is more likely to have taken a more moderate doxastic attitude toward p. I might even think it somewhat likely that MP's doxastic attitude toward p leans in the same direction as my own, since MP's political position is less predictive of his or her substantive view. Either way, I find it much more plausible that the publically available evidence about $\mathrm{p}$ could support a moderate doxastic attitude in the opposite direction of my own than I find it that it could support an extreme attitude in that direction. So, I might think that it is more likely that MP is right than I do that $\mathrm{BP}$ is right. If so, then ABILITY and ACCURACY, which are often thought to be coextensive, or at least strongly positively correlated, are inversely correlated in political disagreements where motivated cognition is at play.

The fact that the two factors yield different verdicts raises the question of which factor we should base our assessment of the epistemic significance of the disagreement on: ABILITY or ACCURACY? Neither verdict seems entirely satisfactory. If we assess the significance of disagreement by reference to ABILITY, then I should give more weight to the disagreement the more likely I think my interlocutor is to be wrong. If we assess the significance of disagreement by reference to ACCURACY, I should give more weight to the disagreement the less familiar I think my interlocutor is with the relevant evidence, and the less competent I think he or she is in processing it. 
Perhaps this apparent conflict is caused by a mistake. Consider that one of the defining qualities of ABILITY is freedom from bias. As BP and MP are subject to motivated reasoning, they are not free from bias. Furthermore, the evidence on motivated reasoning might appear to suggest that BP is more biased than MP is. Perhaps this higher amount of bias cancels out, or even outweighs, the higher levels that BP possesses of the other qualities that make up ABILITY. So taking the total qualities into account, it might be the case that BP does not, in fact, have higher ABILITY than MP does.

However, there are problems with this solution. As it relates to motivated reasoning, to be free from bias means that one's reasoning does not proceed with the goal of defending a particular conclusion, but rather proceeds with the goal of arriving at an accurate assessment of the evidence (Kunda 1990). But in this sense, BP and MP are are equally biased. Both are equally motivated to arrive at the conclusion that is congenial to their political outlook. The difference is that BP is more successful at doing so, because his or her cognitive capacities are put to use in construing the evidence so as to support the desired conclusion, and BP has an advantage over MP with respect to these capacities. Of course, we might take freedom from bias to indicate something else. We might take it to indicate that one's assessment of the evidence yields a construal that is reflective of what the evidence actually supports. But doing so comes close to equating freedom from bias with ACCURACY. This does not seem to be what is normally meant by freedom from bias. What is meant is that one's reasoning is free from any systematically biasing factors, not that one necessarily get things right. The biasing factor in question here is a motivation to arrive at a desired conclusion, and BP and MP have that motivation to equal extent.

Another mistake that might have led to the discrepancy concerns how we construed the verdict yielded by assigning epistemic significance based on ACCURACY. Am I really justified in thinking it less likely that BP is correct than that MP is, merely on the basis that I expect BP's view to be further removed from my own? The reasoning driving that verdict might be something like the following: Suppose that, prior to learning anything about BP or MP, I were to reflect on the possibility that the evidence about $\mathrm{p}$ really supports some other credence than what I currently assign $\mathrm{p}$. I realize that this is in fact a possibility, since I am not perfect at evaluating evidence. As a result, I form a credence distribution over what credence the evidence really supports about p. Plausibly, this credence distribution should have a maximum at the credence I currently assign p. If I didn't think it more likely that the evidence supports my current credence in $\mathrm{p}$ than that it supports some other credence, then I wouldn't have my current credence in $\mathrm{p}$ at all. But what probability should I assign other credences as we move away from my actual one? Plausibly, I shouldn't assign all other credence equal probability. It would be odd for me to think that it is just as likely that the evidence really supports a credence that is as far from my current credence as possible as it is that it supports a credence in the very near vicinity of my current one. So let's suppose that my credence distribution should look something like a normal distribution around my actual credence in $\mathrm{p}$. The farther away from my actual credence we move, the less likely I think it is that the evidence really supports that credence. If so, it seems like I have a 
reason to think that it is less likely that someone with a credence in $\mathrm{p}$ that is very far from my own is correct, compared to someone with a credence closer to my own.

But this line of reasoning will be objectionable to those who are attracted to something like the Independence principle (Christensen 2009). The Independence principle says that I should not use my initial reasoning about $\mathrm{p}$ to assess someone's epistemic credentials when determining the epistemic significance of disagreement. I can only assess it by referring to dispute-independent reasons. But my higher-order credence distribution is based on my initial reasoning about $\mathrm{p}$ : it has the shape it does because I initially judge that my current credence is the right response to the evidence. So assessing BP's or MP's ACCURACY on its basis would amount to a violation of Independence.

However, there is another route to the conclusion that BP has less ACCURACY than MP, which does not run afoul of the Independence principle. BP's brilliance means that he or she is extremely good at coming up with reasons in favor of his or her desired conclusion, and at generating justifications for rejecting any reasons he or she should encounter against it. But BP's ability to come up with these reasons is not very informative about what the evidence actually supports with respect to $\mathrm{p}$. BP's brilliance means that, more or less regardless of what the evidence really supports about $\mathrm{p}$, he or she would be able construe the evidence as supportive, and to conjure up reasons to be supremely confident that his or her desired conclusion about $\mathrm{p}$ is correct. Even when faced with evidence that strongly suggests that BP is wrong about $\mathrm{p}$, he or she is able to creatively wriggle his or her way out of taking that evidence as counting against p. Not so for MP. When faced with strong evidence against his or her favored conclusion, MP does not have the ABILITY necessary to escape from the conclusion that the evidence really warrants decreasing his or her confidence in his or her favored conclusion about p. So MP's belief about $\mathrm{p}$ is more constrained by what the evidence actually supports than BP's belief is. Therefore, I should think that MP has higher ACCURACY than BP does. This line of thought makes no reference to my own reasoning about p. It only makes use of the general claim that, due to BP's brilliance, he or she is generally better able to shape his or her interpretations of the evidence in ways that are congenial to his or her favored conclusions.

\section{Introspection and symmetry}

If the above line of reasoning is correct, then we should think that there is an inverse correlation between ABILITY and ACCURACY in cases of disagreement about politically disputed propositions where we are vulnerable to motivated reasoning. Choosing to base our epistemic assessment on either of these leads to an uncomfortable conclusion. In the next sections, I consider some possible ways to resolve this problem.

One type of solution is to hold that it doesn't matter whether we go with ABILITY or ACCURACY in determining the epistemic significance of political disagreements, because we should not generally consider such disagreements to be epistemically significant, regardless of what standard we go with. Someone might 
hold that, while more isolated instances of disagreement are epistemically significant, the pervasive and persistent kind of disagreement that we find in the political domain does not in the same way require doxastic revision (Elga 2007).

One type of argument that could possibly lead to this conclusion is a debunking argument. BP and MP being biased might give me a reason to disregard their disagreement with me altogether. Why should I take their belief about $\mathrm{p}$ into account at all if I have good reason to suspect that they have arrived at the belief through biased reasoning about the evidence? This type of argument has previously been put forward in the domain of philosophical disagreement. Fumerton (2010) has argued that he often takes himself to have good reason to discount the disagreement of his colleagues, even well-known and respected ones, because he takes them to be subject to motivated reasoning: "Perhaps I have some reason to believe, for example, that [my disagreeing colleagues] are the victims of various biases that cause them to believe what they want to believe. Indeed, I suspect that I do have reason to believe that others are afflicted in such ways..." (2010, p. 102). If we are often justified in thinking this way about our political opposites, it might not be hard at all to determine the epistemic significance of disagreement about politically charged propositions. We should not take them to be significant at all, because we often have dispute-independent reason to think that the views of our interlocutors are the result of motivated reasoning.

But this proceeds too quickly. After all, does motivated reasoning not similarly afflict our own beliefs? What reason do I have to suppose that my own belief about $\mathrm{p}$ is not the result of my political ideology having influenced the way I have sought out and evaluated the relevant evidence? Is there a reason to think that those on the other side of the political aisle are generally subject to motivated reasoning to a greater extent than those on my side of the aisle? There is empirical evidence that suggests not. Liberals and conservatives are equally motivated to arrive at politically congenial conclusions, and are equally likely to fall prey to similar magnitudes of motivated reasoning (Frimer et al. 2017; Hallen et al. 2017; Kahan 2013). Therefore, one's political position by itself provides no independent reason to take oneself to be absolved from the charge of bias, at least not on our current evidence about the political distribution of motivated reasoning.

While the studies showing political symmetry in the degree of motivated reasoning might apply in general, they only show that on average, liberals and conservatives are equally biased. This of course leaves open the possibility that I am not biased. Could I not therefore have some reason to think that I, unlike most other people on both sides of the political aisle, am exempt from bias? While I think that statistical information of this nature should generally influence our beliefs about ourselves (Elga 2005), let us nevertheless explore that question. Fumerton appeals to self-knowledge gained through introspection to argue that he has reason to think that he is not subject to bias to the same extent as other philosophers: "I do, in fact, think that I have got more self-knowledge than a great many other academics I know, and I think that self-knowledge gives me a better and more neutral perspective on a host of philosophical and political issues" (Fumerton 2010, p. 102). Following this line of thought, Fumerton takes himself to be justified in downgrading the epistemic significance of some philosophical disagreements by 
attributing motivated reasoning to his colleagues and exempting himself through introspective evidence of the absence of bias. So perhaps we can apply the same line of reasoning in cases of political disagreement more generally.

I doubt that this strategy will be successful, largely for the kinds of reasons presented by Ballantyne (2015). Consider that among the many documented biases in human cognition is the so-called bias blind-spot (Pronin et al. 2002). The biasblind spot refers to a sort of meta-bias, a broad tendency to readily attribute biases to others, while considering one's own cognition to be objective and neutral, even when it is in fact biased. Bias blind-spot, and other research indicating that introspection is generally an unreliable process of generating beliefs about one's own cognitive processes (Carruthers 2011; Nisbett and Wilson 1977), suggests that one would seldom be justified in attributing motivated reasoning to others but absolving one self on the basis of introspection. Bias blind-spot implies that one is not justified in using attributions of motivated reasoning as a symmetry breaker unless one has independent reason outside of introspection to exculpate oneself. It might be true that one's interlocutor is subject to motivated reasoning, but I might have no independent reason to suspect that I am not subject to the same extent, even if introspection seems to suggest that I am not.

Someone arguing along Fumerton's lines might reply that his substantial selfknowledge includes his knowledge that bias blind-spot and motivated reasoning is a risk in his own thinking about politically disputed propositions. In cases of disagreement, this awareness causes him to take extra care to make sure that his reasoning is unbiased. Since he knows that he has sincerely attempted to correct for bias, but he does not know that his interlocutors have done so, he has personal information that can serve as a relevant symmetry breaker (Lackey 2008). But this reply is unsatisfactory. In fact, a general knowledge of the existence of motivated reasoning and bias blind spot can put one at risk of succumbing to the bias to an even greater extent than one would in the absence of such knowledge. Suppose that you reason from some evidence to $\mathrm{p}$. Because of your awareness of the existence of motivated reasoning, and of the blind spot that makes its operation opaque to yourself, you make sure to double-check that your reasoning is strong. You introspect on any motivations you might have that could have led you to want to conclude $\mathrm{p}$. You revisit the evidence and reaffirm its actual bearing on $\mathrm{p}$, etc. The problem is that this is highly unlikely to be an effective method of discovering and correcting for the impact of motivated reasoning. Even if your initial reasoning was biased, introspection is unlikely to reveal it, even if you actively search for it. And, having failed to detect bias in your reasoning, you might wrongly conclude that your original reasoning was indeed strong and unbiased. Furthermore, your having made every attempt to eliminate bias as an explanation of your belief that $\mathrm{p}$ might lead you to become more confident than you were initially that $\mathrm{p}$ is correct. In this way, biased belief is often made even more biased by attempts to be objective in one's reasoning (Kenyon 2014; Lord et al. 1984; McPherson Frantz and Janoff-Bulman 2000). So while it may be perfectly reasonable to debunk the epistemic position of someone on the other side of the political aisle by attributing motivated reasoning to them, one will rarely be justified in absolving oneself of the same debunking by reference to introspection. 
This response to the debunking argument also presents a problem for a potential solution to the conflict between ABILITY and ACCURACY. Recall that my reason for downgrading BP's ACCURACY was roughly that the normal correlation between ABILITY and my subjective probability of BP being correct is reversed in the case of politically divisive propositions. Because BP is able to ingeniously construe evidence as supportive of his or her desired conclusion regardless of what the evidence actually supports, I should think it less likely that BP's belief is correct when we disagree. But without such a positive correlation, there seems to be no motivation to adjust my view on the basis of BP's ABILITY at all (King 2012). Why should one put any particular stock in the disagreement of a genius if one expects the genius to be mistaken about matter under dispute? Absent a reason to think that ABILITY correlates positively with ACCURACY in cases of political disagreement, perhaps we should ignore ABILITY altogether and assess epistemic credentials on the basis of ACCURACY.

While this solution certainly has some initial draw, it leads to an odd consequence. Plausibly, if I assess someone's epistemic credentials by reference to their ACCURACY, I should do the same for my own. But we have seen that I may have no reason to think that I am less likely to be subject to motivated reasoning than my interlocutor is. Therefore, I should apply the same reasoning that I did with respect to my interlocutor's ACCURACY to my own. The higher my own ABILITY, the less constrained my doxastic attitude is likely to be by the actual force of the evidence. The consequence of that line of thought seems to be that I should think it less likely that I am right the more familiar I am with the relevant evidence, and the higher I rate myself with respect to the various intellectual virtues that make up ABILITY. But this conclusion seems rather counterintuitive, and would appear to imply that I should think that I would improve the rationality of my political beliefs by avoiding evidence or by taking steps to hamper by own cognition. ${ }^{6}$

\section{Clustering}

Elga (2007) offers a different line of argument for denying the epistemic significance of political disagreements. He asks us to consider a disagreement about the permissibility of abortion between two friends, Ann and Beth, who are on opposite sides of the political spectrum: "Does Ann consider Beth a peer with respect to [the claim that abortion is morally permissible]? That is: setting aside her own reasoning about the abortion claim (and Beth's contrary view about it), does Ann think Beth would be just as likely as her to get things right? The answer is "no". For (let us suppose) Ann and Beth have discussed claims closely linked to the abortion claim. They have discussed, for example, whether human beings have souls, whether it is permissible to withhold treatment from certain terminally ill

\footnotetext{
${ }^{6}$ Although he emphasizes different psychological mechanisms than I have here, Levy (2006) has suggested that we sometimes should in fact avoid evidence about politically divisive propositions, when seeking out and evaluating such evidence carries a significant risk of worsening our epistemic position.
} 
infants, and whether rights figure prominently in a correct ethical theory. By Ann's lights, Beth has reached wrong conclusions about most of these closely related questions. As a result, even setting aside her own reasoning about the abortion claim, Ann thinks it unlikely that Beth would be right in case the two of them disagree about abortion" (Elga 2007, p. 493).

So on Elga's view, another reason one might have to reject the epistemic significance of political disagreements is that the clustering of beliefs about politically disputed propositions gives one dispute-independent reason to denigrate the epistemic standing of someone from the other side of the aisle. When I know something about a person's political position, as I do in BRILLIANT PARTISAN and MEDIOCRE PARTISAN, or if I know what they believe about a particular politically disputed proposition $\mathrm{p}$, then I can infer something about their likely position on other politically disputed propositions q, r, and s. For example, if I know that someone is a liberal democrat, or if I know that they believe that humans are causing global warming, then I can make a qualified guess about what they believe about the death penalty, abortion, gun control, or marihuana legalization (Kahan 2015; Kahan et al. 2007). And I can use my belief that they are wrong about these other, but related, disagreements, to downgrade their epistemic position with respect to $\mathrm{p}$, without thereby violating the Independence principle.

I am not convinced that this kind of argument is sufficient for the denying epistemic significance of political disagreements. Consider that our respective political positions can be taken as a common determinant of our beliefs about p, q, r, and s. If I can justifiably use the fact that, by my lights, you are wrong about q, r, and s, to downgrade your epistemic standing with respect to $\mathrm{p}$, then this would amount to my being justified in thinking that my political position is generally more conducive to ACCURACY than yours is. But why should we think that I have dispute-independent reason to think that this is the case? The evidence on the political symmetry of motivated reasoning suggests that we are equally likely to have misconstrued the evidence so as to favor our politically congenial conclusions for all these propositions. To insist otherwise seems to be an instance of bias blind spot. But if I have no reason to think that I have been more objective in evaluating the evidence with respect to $\mathrm{q}, \mathrm{r}$, and s, than you have, then it seems rather suspect to use my judgment about these propositions to downgrade your epistemic standing with respect to $\mathrm{p}$.

\section{Reasons to downgrade}

The above suggests that neither debunking arguments nor clustering arguments allow us to deny the epistemic significance of political disagreements in general. However, this is not to suggest that it is always the case that political disagreements are epistemically significant. Sometimes, we do have dispute-independent reason to downgrade the epistemic standing of our interlocutor with respect to particular politically divisive propositions. For example, the fact that the vast majority of climate scientists agree that humans are causing global warming, and the fact that such a verdict correlates with level of expertise in climate science, is one such 
reason (Cook et al. 2013, 2016; Oreskes 2005). I think it is plausible that this fact gives a dispute-independent reason for someone who believes that humans are causing global warming to downgrade the epistemic standing of an interlocutor with respect to that question.

But many political disagreements are not such that there is an overwhelming expert consensus or similar dispute-independent ways to settle an issue. What I have argued is that absent such reasons, it rarely will be the case that one will be justified in downgrading someone's epistemic credentials on the basis of any purported differences in the quality or objectivity of reasoning that stem from political ideology. Even when someone's belief about $\mathrm{p}$ actually reflects what the best evidence supports, this is not necessarily due to their having been any less biased in their reasoning about the relevant evidence than their interlocutor. Consider for example that people who believe that humans are causing global warming are, on the whole, no more likely to answer basic questions about climate science correctly than are people who deny it, and are equally likely to misconstrue evidence as being more supportive of their desired conclusion with respect to global warming than it is (Kahan 2013, 2015). Even if we grant that the believer in anthropogenic global warming is in a superior epistemic position, this is not the result of a better understanding of climate science or more objective assessments of the evidence. Neither is it likely due to a greater general tendency to defer to scientific expertise. Although there is a correlation between political ideology and general trust in science (Hamilton 2015; Nadelson et al. 2014), ideology does not explain much of the variance, ${ }^{7}$ and science is one of the, if not the, most trusted institutions in society among liberals and conservatives alike, just as conservatives and liberals alike trust scientists about the vast majority of issues. ${ }^{8}$ But like reasoning, our trust in science can be politically motivated (McCright et al. 2013). Whether we judge someone as a true expert tends to depend on whether they expound views that are congenial to our political beliefs (Kahan et al. 2011). Liberals, who tend to trust climate scientists about global warming, are, for example, more likely to dispute the scientific consensus about the safety of nuclear energy than a denier of global warming is (Nisbet et al. 2015; Peters and Slovic 1996; Pew Research Center 2015; cf. Hamilton 2015). The superior epistemic position of those who believe in anthropogenic global warming is perhaps rather due, at least in part, to epistemic luck (Pritchard 2005). They are fortunate enough that in this particular case, their political ideology has inclined them toward the factual belief that reflects the scientific consensus and what the evidence really supports. But in other cases of political disagreement, there may be no such luck, and in such cases the disagreement will be of epistemic significance.

\footnotetext{
7 For example, political ideology explains just $2 \%$ of the variance in general trust in science in Nadelson et al. (2014).

${ }^{8}$ http://www.culturalcognition.net/blog/2014/11/25/conservatives-lose-faith-in-science-over-last-40-yearswhere.html.
} 


\section{Concluding remarks}

Disagreements about politically divisive propositions are, then, often more epistemically significant than they have sometimes been perceived to be within the epistemology of disagreement. This leaves us with the unresolved puzzle of whether to ascertain the epistemic significance of such disagreements on the basis of ABILITY or ACCURACY. I have no hard answer to give here-it seems to me to be a genuine puzzle with unwelcome consequences whichever route we go.

Instead, I close by suggesting that what holds for politics may hold for other divisive domains that plausibly evoke motivated reasoning, such as morality, and (for philosophers) philosophy. While I know of no direct evidence on this, it seems a distinct possibility that a similar empirical pattern might hold here-that as ABILITY increases; so does doxastic polarization within these domains. If so, disputants in these domains face the same problem that perceived ABILITY and ACCURACY are inversely correlated, and the task of adjudicating between these two in assessing the epistemic significance of disagreement.

Acknowledgements I would like to thank David Christensen, Hélène Landemore, Joshua HabgoodCoote, Klemens Kappel, Mikkel Gerken, Fernando Broncano-Berrocal, Jeroen de Ridder, Annette Martin, Chris Ranalli, Mariangela Zoe Cocchiaro, and Udit Bhatia, for helpful comments and discussion during the workshop in Social and Political Epistemology at the University of Copenhagen in March 2018. I also thank an anonymous reviewer for helpful suggestions.

Funding The work that resulted in this article was made possible by a grant from the Danish Free Research Councils (No. 4001-00059B FKK).

\section{References}

Balcetis, E., \& Dunning, D. (2006). See what you want to see: Motivational influences on visual perception. Journal of Personality and Social Psychology, 91(4), 612-625. https://doi.org/10.1037/ 0022-3514.91.4.612.

Ballantyne, N. (2015). Debunking biased thinkers (including ourselves). Journal of the American Philosophical Association, 1(1), 141-162. https://doi.org/10.1017/apa.2014.17.

Carruthers, P. (2011). The opacity of mind: An integrative theory of self-knowledge. Oxford: Oxford University Press. https://doi.org/10.1093/acprof:oso/9780199596195.001.0001.

Christensen, D. (2007). Epistemology of disagreement: The good news. Philosophical Review, 116(2), 187-217. https://doi.org/10.1215/00318108-2006-035.

Christensen, D. (2009). Disagreement as evidence: The epistemology of controversy. Philosophy Compass, 4(5), 756-767. https://doi.org/10.1111/j.1747-9991.2009.00237.x.

Christensen, D. (2010). Higher-order evidence. Philosophy and Phenomenological Research, LXXXI(1), 185-215. https://doi.org/10.1111/j.1933-1592.2010.00366.x.

Christensen, D. (2014). Disagreement and public controversy. In J. Lackey (Ed.), Essays in collective epistemology (pp. 1-33). Oxford: Oxford University Press.

Christensen, D. (2016). Conciliation, uniqueness and rational toxicity. Noûs, 50(3), 584-603. https://doi. org/10.1111/nous.12077.

Christensen, D., \& Lackey, J. (2013). The epistemology of disagreement: New essays. In J. Lackey (Ed.), Christensen D. Oxford: Oxford University Press.

Cook, J., Nuccitelli, D., Green, S. A., Richardson, M., Winkler, B., Painting, R., et al. (2013). Quantifying the consensus on anthropogenic global warming in the scientific literature. Environmental Research Letters. https://doi.org/10.1088/1748-9326/8/2/024024. 
Cook, J., Oreskes, N., Doran, P. T., Anderegg, W. R. L., Verheggen, B., Maibach, E. W., et al. (2016). Consensus on consensus: A synthesis of consensus estimates on human-caused global warming. Environmental Research Letters. https://doi.org/10.1088/1748-9326/11/4/048002.

Corner, A., Whitmarsh, L., \& Xenias, D. (2012). Uncertainty, scepticism and attitudes towards climate change: Biased assimilation and attitude polarisation. Climatic Change, 114(3-4), 463-478. https:// doi.org/10.1007/s10584-012-0424-6.

Elga, A. (2005). On overrating oneself... and knowing it. Philosophical Studies, 123(1-2), 115-124. https://doi.org/10.1007/s11098-004-5222-1.

Elga, A. (2007). Reflection and disagreement. Noûs, 41(3), 478-502. https://doi.org/10.1111/j.1468-0068. 2007.00656.x.

Enoch, D. (2017). Political philosophy and epistemology. Oxford Studies in Political Philosophy, 3, 132-165. https://doi.org/10.1093/oso/9780198801221.001.0001.

Feldman, R. (2006). Epistemological puzzles about disagreement. In S. Hetherington (Ed.), Epistemology futures (pp. 126-236). Oxford: Oxford University Press.

Feldman, R., \& Warfield, T. A. (2010). Disagreement. Oxford: Oxford University Press. Retrieved from http://www.amazon.co.uk/Disagreement-Richard-Feldman/dp/0199226083.

Frimer, J. A., Skitka, L. J., \& Motyl, M. (2017). Liberals and conservatives are similarly motivated to avoid exposure to one another's opinions. Journal of Experimental Social Psychology, 72(April), 1-12. https://doi.org/10.1016/j.jesp.2017.04.003.

Fumerton, R. (2010). You can't trust a philosopher. In R. Feldman \& T. A. Warfield (Eds.), Disagreement (p. 91). Oxford: Oxford University Press. https://doi.org/10.1093/acprof.

Gelfert, A. (2011). Who is an epistemic peer? Logos and Episteme, 2(4), 507-514.

Hallen, B. L., Bingham, C. B., Hill, C., Carolina, N., \& Cohen, S. L. (2017). At least bias is bipartisan: A meta-analytic comparison of partisan bias in liberals and conservatives. SSRN: https://ssrn.com/ abstract=2952510, April 3. http://doi.org/10.1007/s10551-015-2769-z.For.

Hamilton, L. C. (2011). Education, politics and opinions about climate change: Evidence for interaction effects. Climatic Change, 104(2), 231-242. https://doi.org/10.1007/s10584-010-9957-8.

Hamilton, L. C. (2015). Conservative and liberal views of science. The Carsey school of public policy at the scholars' repository, paper 252. Retrieved from http://scholars.unh.edu/carsey/252.

Hart, W., Albarracín, D., Eagly, A. H., Brechan, I., Lindberg, M. J., \& Merrill, L. (2009). Feeling validated versus being correct: A meta-analysis of selective exposure to information. Psychological Bulletin, 135(4), 555-588. https://doi.org/10.1037/a0015701.

Hennes, E. P., Ruisch, B. C., Feygina, I., Monteiro, C. A., \& Jost, J. T. (2016). Motivated recall in the service of the economic system: The case of anthropogenic climate change. Journal of Experimental Psychology: General, 145(6), 755-771. https://doi.org/10.1037/xge0000148.

Kahan, D. M. (2012). Cultural cognition as a conception of the cultural theory of risk. In S. Roeser, R. Hillerbrand, M. Sandin, \& M. Peterson (Eds.), Handbook of risk theory (p. 725). Berlin: Springer. https://doi.org/10.1007/978-94-007-1433-5.

Kahan, D. M. (2013). Ideology, motivated reasoning, and cognitive reflection. Judgment and Decision Making, 8(4), 407-424.

Kahan, D. M. (2015). Climate-science communication and the measurement problem. Political Psychology, 36(S1), 1-43. https://doi.org/10.1111/pops.12244.

Kahan, D. M. (2016). The Politically Motivated Reasoning Paradigm Part 1: What Politically Motivated Reasoning Is and How to Measure It. In Emerging trends in social \& behavioral sciences: An interdisciplinary, searchable, and linkable resource, pp. 1-16.

Kahan, D. M., Braman, D., Gastil, J., Slovic, P., \& Mertz, C. K. (2007). Culture and identity-protective cognition: Explaining the white male effect in risk perception. Journal of Empirical Law Studies, 4(3), 465-505. https://doi.org/10.1111/j.1740-1461.2007.00097.x.

Kahan, D. M., \& Corbin, J. C. (2016). A note on the perverse effects of actively open-minded thinking on climate-change polarization. Research \& Politics. https://doi.org/10.1177/ 2053168016676705.

Kahan, D. M., Jenkins-Smith, H., \& Braman, D. (2011). Cultural cognition of scientific consensus. Journal of Risk Research, 14(2), 147-174. https://doi.org/10.1080/13669877.2010.511246.

Kahan, D. M., Peters, E., Dawson, E. C., \& Slovic, P. (2017). Motivated numeracy and enlightened selfgovernment. Behavioural Public Policy, 1(1), 54-86. https://doi.org/10.1017/bpp.2016.2.

Kahan, D. M., Peters, E., Wittlin, M., Slovic, P., Ouellette, L. L., Braman, D., et al. (2012). The polarizing impact of science literacy and numeracy on perceived climate change risks. Nature Climate Change, 2(10), 732-735. https://doi.org/10.1038/nclimate1547. 
Kahan, D. M., \& Stanovich, K. E. (2016). Rationality and belief in human evolution. Annenberg public policy center working paper no. 5. Retrieved from https://ssrn.com/abstract=2838668.

Kelly, T. (2005). The epistemic significance of disagreement. In J. Hawthorne \& T. S. Gendler (Eds.), Oxford studies in epistemology (Vol. 1, pp. 1-36). Oxford: Oxford University Press.

Kelly, T. (2010). Peer disagreement and higher order evidence. In R. Feldman \& T. A. Warfield (Eds.), Disagreement (p. 183). Oxford: Oxford University Press.

Kelly, T. (2013). Disagreement and the burdens of judgment. In D. Christensen \& J. Lackey (Eds.), The epistemology of disagreement: New essays. Oxford: Oxford University Press. https://doi.org/10. 1093/acprof:oso/9780199698370.001.0001.

Kenyon, T. (2014). False polarization: Debiasing as applied social epistemology. Synthese. https://doi. org/10.1007/s 11229-014-0438-x.

King, N. L. (2012). Disagreement: What's the problem? Or a good peer is hard to find. Philosophy and Phenomenological Research, 85(2), 249-272. https://doi.org/10.1111/j.1933-1592.2010.00441.x.

Kraft, P. W., Lodge, M., \& Taber, C. S. (2015). Why people "don't trust the evidence": Motivated reasoning and scientific beliefs. Annals of the American Academy of Political and Social Science, 658(1), 121-133. https://doi.org/10.1177/0002716214554758.

Kunda, Z. (1990). The case for motivated reasoning. Psychological Bulletin, 108(3), 480-498. https://doi. org/10.1037/0033-2909.108.3.480.

Lackey, J. (2008). A justificationist view of disagreement's epistemic significance. In A. Haddock, A. Millae, \& D. Pritchard (Eds.), Social epistemology. Oxford: Oxford University Press. https://doi.org/ 10.1093/acprof.

Levy, N. (2006). Open-mindedness and the duty to gather evidence. Public Affairs Quarterly, 20(1), 55-66.

Lord, C. G., Lepper, M. R., \& Preston, E. (1984). Considering the opposite: A corrective strategy for social judgment. Journal of Personality and Social Psychology, 47(6), 1231-1243. https://doi.org/ 10.1037/0022-3514.47.6.1231.

Lord, C. G., Ross, L., \& Lepper, M. R. (1979). Biased assimilation and attitude polarization: The effects of prior theories on subsequently considered evidence. Journal of Personality and Social Psychology, 37(11), 2098-2109.

Matheson, J. D. (2015). The epistemic significance of disagreement. Palgrave Innovations in Philosophy. https://doi.org/10.1007/s13398-014-0173-7.2.

McCright, A. M., Dentzman, K., Charters, M., \& Dietz, T. (2013). The influence of political ideology on trust in science. Environmental Research Letters. https://doi.org/10.1088/1748-9326/8/4/044029.

McPherson Frantz, C., \& Janoff-Bulman, R. (2000). Considering both sides: The limits of perspective taking. Basic and Applied Social Psychology, 22(1), 31-42. https://doi.org/10.1207/S15324834BASP2201_4.

Nadelson, L., Jorcyk, C., Yang, D., Jarratt Smith, M., Matson, S., Cornell, K., et al. (2014). I just don't trust them: The development and validation of an assessment instrument to measure trust in science and scientists. School Science and Mathematics, 114(2), 76-86. https://doi.org/10.1111/ssm.12051.

Nisbet, E. C., Cooper, K. E., \& Garrett, R. K. (2015). The partisan brain: How dissonant science messages lead conservatives and liberals to (dis)trust science. Annals of the American Academy of Political and Social Science, 658(1), 36-66. https://doi.org/10.1177/0002716214555474.

Nisbett, R., \& Wilson, T. (1977). Telling more than we can know: Verbal reports on mental processes. Psychological Review, 84(3), 231-259.

Oreskes, N. (2005). The scientific consensus on climate change. Science, 306(January), 2004-2005. https://doi.org/10.1126/science.1103618.

Peters, E., \& Slovic, P. (1996). The role of affect and worldviews as orienting dispositions in the perception and acceptance of nuclear power. Journal of Applied Social Psychology, 26(16), 1427-1453. https://doi.org/10.1111/j.1559-1816.1996.tb00079.x.

Pew Research Center. (2015). Public and scientists' views on science and society, January 29.

Pritchard, D. (2005). Epistemic luck. Oxford: Oxford University Press. https://doi.org/10.1093/ 019928038X.001.0001.

Pronin, E., Lin, D. Y., \& Ross, L. (2002). The bias blind spot: Perceptions of bias in self versus others. Personality and Social Psychology Bulletin, 28(3), 369-381. https://doi.org/10.1177/ 0146167202286008.

Taber, C. S., \& Lodge, M. (2006). Motivated skepticism in the evaluation of political beliefs. American Journal of Political Science, 50(3), 755-769.

Van Bavel, J. J., \& Pereira, A. (2018). The partisan brain: An identity-based model of political belief the role of identity in political belief. Trends in Cognitive Sciences, XX, 1-12. https://doi.org/10.1016/j. tics.2018.01.004. 